\title{
Erratum to: Identification and characterization of the rhizosphere phosphate-solubilizing bacterium Pseudomonas frederiksbergensis JW-SD2, and its plant growth-promoting effects on poplar seedlings
}

\author{
Qingwei Zeng ${ }^{1} \cdot$ Xiaoqin $\mathrm{Wu}^{1} \cdot$ Xinyi Wen ${ }^{1}$
}

Published online: 18 February 2017

(C) Springer-Verlag Berlin Heidelberg and the University of Milan 2017

Erratum to: Ann Microbiol (2016) 66:1343-1354

DOI 10.1007/s13213-016-1220-8

This article has been updated at some points and was published as a new publication under DOI 10.1007/s13213-0161237-z. This article will no longer be indexed and all current citations of this article will be transferred to the new publication.

The authors and the editors wish to note that the second publication was caused by an honest mistake that lead to this double publication. The authors and the editors apologize for any inconvenience this might have caused.

The online version of the original article can be found at http://dx.doi.org/ 10.1007/s13213-016-1220-8.

Xinyi Wen

xqwu@njfu.edu.cn

1 Co-Innovation Center for Sustainable Forestry in Southern China, College of Forestry, Nanjing Forestry University, Room 1217, 159

Longpan Road, Nanjing, Jiangsu 210037, China 